with ordinary life." What is really required is specialization and general education. At the new university in North Staffordshire (Stoke) it is proposed to start a general course for students who will not know whether they are science or arts students in the first year. They will follow one course and thereby all have a common background of understanding. Since one of the regrettable academic trends in recent years has been the excessive departmentalization in technology and science it is hoped to form a community with a common aim and thought in North Staffordshire in which the professors will form an essential part.

Lord Lindsay then raised the question of what part the universities can play in education for management. He suggested that management needs certain technical information which can be learned in technical colleges, but that the university should only be concerned with providing future managers with a critical faculty and showing them the relevance of their subject studies to matters which are not specialized. The universities should not provide a special course in management and there should not be people in universities studying for a "B. Man" degree living together as potential managers. A student at the university who hopes to go into business management should study something that has a strong sociological side, like Oxford Modern Greats. At the university they should also be given a sociological bent of mind, the ability to see the importance of structure in organisation and groups.

T. H. HAWkINS

\section{CONSTITUTION OF MARS}

A

PAPER by K. E. Bullen, "On the Constitution of Mars"1, suggests that the earth and Mars are of the same primitive composition. On the basis of an earth model-referred to in the paper as model $A$ - which was advocated by Bullen in "An Introduction to the Theory of Seismology" (1947), W. H. Ramsey assumed that the density variation in the earth's deep interior is essentially determined by pressure rather than by changes in the materials present, and found a discrepancy in fitting the planet Mars to the hypothesis that the terrestrial planets are of the $\operatorname{sam} \theta$ primitive composition. The discrepancy is considerably less than that found by $H$. Jeffreys on the hypothesis that the large change in density across the boundary of the earth's central core is due to a change of material rather than to pressure. Ramsey showed that the discrepancy could be removed if model $A$ were modified to include an allowance for the gravitation of the heavier elements towards the centre of the earth.

In the present paper, Bullen shows that the discrepancy is fully removed by an earth model $B$ instead of $A$, model $B$ being constructed on the basis of a compressibility-pressure hypothesis. In this model there is a sharp density increase from $3 \cdot 36$ to $3 \cdot 37$ $\mathrm{gm}$. $/$ c.c. at a depth of $80 \mathrm{~km}$., followed by a fairly steady density gradient down to a depth of $2,700 \mathrm{~km}$. After this the gradient increases sharply for the next $200 \mathrm{~km}$., the density being $5.57 \mathrm{gm}$. $/$ c.c. at the base of the mantle. Inside the central core the density ranges from $9 \cdot 74$ to $12 \mathrm{gm}$./c.c. at a depth of 4,980 $\mathrm{km}$., and then rises sharply, reaching a value of 17$18 \mathrm{gm} . / \mathrm{c} . c$. at the centre. This model is independent of the observations of the radius and mass of Mars and Venus, so that no ad hoc adjustments are involved in fitting it to the planets. In fitting Mars to the hypothesis of the same primitive composition for the terrestrial planets, the most satisfactory agreement is obtained on the assumption that Mars has an inner core in the same proportion by mass as the earth.

The calculations show that the results are consistent with a large proportion of nickel-iron in the inner cores of the planets, and some higher-density additional material. The subject is also discussed by Bullen and Ramsey².

${ }^{1}$ Bullen, K. E., Mon. Not. Roy. Astro. Soc., 109, 6 (1949). ' Bullen, K. E., and Ramsey, W. H., Mon. Not. Roy. Astro. Soc.,
Geophys. Supp., 6, 1 (1950).

\section{AIR HYGIENE AND AIRBORNE INFECTION}

A SPECIAL report of the Medical Research 1 Council, entitled "Studies in Air Hygiene"*, is a symposium written chiefly by a group of workers led by Dr. R. B. Bourdillon, who continued the work on problems of airborne infection and air disinfection begun under the direction of the late Sir Patrick Laidlaw and continued under Dr. C. H. Andrewes. It states in the preface that this publication must be accepted as a landmark in the study of air hygiene. Not only have various practical methods of air disinfection been discussed and compared, but also a reliable and easy technique for the quantitative estimation of bacterial contamination of the air has been found.

The work described in the report falls into four sections : first, there are detailed accounts of instruments developed for sampling air and experimental and theoretical examinations of factors which influence the efficiency of these instruments ; second, the report discusses practical methods of air-disinfection, special attention being directed to the value of the aliphatic alpha-hydroxy-carboxylic acids ; third, field studies of the levels of bacterial contamination of the air in theatres, homes, factories, etc., are described; and fourth, the report discusses a few animal experiments on the transmission of airborne infections. A critical evaluation of the different methods of air disinfection ends the report, of which the appendixes and five pages of references to the literature enhance its value.

Field trials now in progress will help to decide whether improved air hygiene will result in improved health. At present, the preface to the report warns us, we must not assume that unselective reduction of the number of bacteria in the air of buildings will necessarily reduce the number of overt infections of people living in them. On the other hand, Dr. L. Colebrook and his colleagues at the Birmingham Accident Hospital have shown that secondary infection of burns can be largely eliminated by strict aseptic technique carried out in a room ventilated by an abundant stream of filtered air; effective methods of laying blanket-dust have reduced crossinfection in fever and surgical wards ; and appropriate methods of air hygiene have protected industrial workers from dangerous bacteria.

* Medical Research Council. Special Report Series No. 262 : Studies in Air Hygiene. By R. B. Bourdillon, O. M. Lidwell and J. E. Lovelock ; with W. C. Cawston, L. Colebrook, F, P. Ellis, M. van den Ende, R. E. Glover, A. M. Macfarlan, A. A. Miles, W. F. Raymond, H.M. Stationery Office, 1948.) $7 s$. $6 d$. net. 